CANCER AND PALLIATIVE CARE

\title{
Exploring community nurses' perceptions of life review in palliative
}

\section{care}

\author{
Ian Trueman MSc, RGN
}

Health Lecturer, School of Nursing, University of Nottingham, Education Centre, County Hospital Lincoln, Lincoln, UK

Jonathan Parker MA, CQSW, ILTM

Senior Lecturer and Head of Social Work, Faculty of Health and Social Care, University of Hull, Hull, UK

Submitted for publication: 12 March 2004

Accepted for publication: 9 March 2005

\author{
Correspondence: \\ Ian Trueman \\ Health Lecturer \\ School of Nursing \\ University of Nottingham \\ Education Centre \\ County Hospital Lincoln \\ Greetwell Road \\ Lincoln LN2 5QY \\ UK \\ Telephone: +44 (0) 1522573932 \\ E-mail: ian.trueman@nottingham.ac.uk
}

TRUEMAN I \& PARKER J (2006) Journal of Clinical Nursing 15, 197-207

\section{Exploring community nurses' perceptions of life review in palliative care}

Aims and objectives. This exploratory study aimed to identify community nurses' understanding of life review as a therapeutic intervention for younger people requiring palliative care. The objectives set out to: (i) Describe the participants' understanding of reminiscence and life review (ii) Detail their current ideas regarding a structured approach to using life review in the community setting. (iii) Outline their understanding of the possible advantages and limitations of life review in relation to palliative care. (iv) Identify future training requirements.

Background. The literature review illustrated how the eighth developmental stage of Erikson's theory, ego-integrity vs. despair, is a 'crisis' often faced by older people entering the final stage of life. Life review is considered a useful therapeutic intervention in the resolution of this crisis. Younger terminally ill people in the palliative stage of an illness may face the same final crises due to their reduced lifespan. Therefore, this study explored the benefits and limitations of life review as an intervention in palliative care.

Method. The study used a purposive sample of community nurses responsible for delivering generic and specialist palliative care. A qualitative method of data collection in the form of three focus group interviews was used. Subsequent data were manually analysed, categorized and coded with associations between the themes identified.

Results. The findings suggested that community nurses have limited knowledge pertaining to the use of life review and tend to confuse the intervention with reminiscence. Furthermore, they believed that life review could potentially cause harm to practitioners engaged in listening to another person's life story. However, the participants concur that with appropriate training they would find life review a useful intervention to use in palliative care.

Conclusions. The results led to the identification of a number of key recommendations: Community nurses require specific education in the technicalities of life review and additional interpersonal skills training. The need for formalized support through clinical supervision is also recognized and discussed. Finally, suggestions are offered regarding the need to generate wider evidence and how, possibly, to integrate life review into existing palliative care services.

Relevance to clinical practice. This study has demonstrated that community nurses are keen to extend the support offered to younger terminally ill people who are in 
the palliative stage of their illness. Despite having limited knowledge of life the main components and underpinning theory pertaining to life review participants could appreciate the potential of life review as a therapeutic intervention in palliative care and were keen to learn more about its use and gain the necessary knowledge and skills.

Key words: community nursing, education, ego-integrity, life review, palliative care

\section{Introduction}

Within the United Kingdom, there appears to be the common expectation that extended longevity is the norm (Phillipson 1998). However, such aspirations are destroyed with the onset of a terminal illness. Chochinov and Breitbart (2000) add that individuals' anticipated life trajectories and perceptions of themselves need adjusting as the prospect of growing old becomes unattainable. Such news often leaves people bewildered, yearning for a future that is different to the one they now face and they may harbour feelings of regret, helplessness and hopelessness (Borden 1989, McDougall et al. 1997, Brady 1999). Once a person's prognosis suggests that they are entering their final year of life palliative care services are often commenced, an integral component of which may involve community nurses undertaking regular but rather inchoate 'support' visits to discuss physical symptoms and 'develop a rapport' with the patient (Seale 1992).

This descriptive study explores the perceptions of community nurses concerning the potential use of life review as a therapeutic intervention in palliative care. It is proposed that the development of life review technologies might further aid the development, structure and focus of future 'support' visits. Many health and social care professionals may competently facilitate life review work and recommendations relate to the use and development of life review in the context of palliative care.

\section{Theoretical background}

The use of life review as a therapeutic intervention for people requiring palliative care is grounded in the life-stage developmental theories of Erikson (1982), who advanced Freud's biological and psychosexual models of development and concentrated on the development of identity, ego and social concerns. He asserted that development continued beyond puberty, covering the entire human life span. Erikson identified eight psychosocial stages, 'The eight ages of man'. Development and maturation is assumed to be achieved through the resolution of a particular 'crisis' associated with each of the stages (Erikson 1965, 1982).
Erikson (1982) considers ego-integrity vs. despair to be the final 'crisis' in a person's life. It therefore tends to be associated with older people although he refrains from defining when a person reaches old age in chronological terms, suggesting rather that it is measured through an accumulation of losses and adjustments. Havighurst (1972) and Miller (1999) concur, adding that such adjustments could include a decrease in income, physical strength, social activities and health and an increase in a sense of inadequacy. The accumulation of losses approach to understanding ageing is challenged (Brändstädter \& Greve 1994, Coleman 1997, Nolan et al. 2001). Indeed, there are less nihilistic views of ageing that indicate that a sense of personal continuity or biography developed through the experience of losses and adjustments might be possible (Bornat et al. 2000). It may be more balanced to consider that both responses are possible depending on the experiences, trajectory and resiliencies of the individuals involved. However ageing is considered, it is possible to identify certain associations with an Eriksonian model of development if it is seen to be fluid rather than rigid in its application. Erikson (1982) believes that those able to resolve the 'crisis' and achieve ego-integrity increase the likelihood of meaning and order in their life. Conversely, those who do not may become preoccupied with their failures and bad decisions, leading to feelings of regret over their lives and fearing death. Coleman (1986) and Cook (1991) suggest that individuals able to take the long term view that their life had meaning and purpose and are able to reach an acceptance that their experiences were inevitable and could only happen when and how they did, have achieved ego-integrity. Simply put, ego-integrity is the feeling of well being associated with satisfaction in one's life.

It is proposed that Erikson's (1982) belief that the 'crisis' of ego-integrity vs. despair is not solely dependent on age, holds relevance for younger people diagnosed with a terminal illness and their newly found situation along their life span. This is a view echoed by Rancour (2002) who argues that when a life-threatening illness is encountered, patients are immediately catapulted forward to face developmental tasks incongruent with their chronological age. What is known from crisis theory is that people faced with an emotionally 
hazardous situation whose usual coping mechanisms do not work to resolve the psychological distress and feelings of lack of control are more amenable to trying novel interventions (Caplan 1961, Parker \& Bradley 2003). Life review may offer such an interventive modality designed to achieve bonadaption to the crisis situation experienced.

Life review may be regarded as an important developmental task in older adulthood to facilitate ego-integrity, through which individuals are given the opportunity to integrate past experiences, whilst valuing the present with an eye on the future (Erikson 1982, Coleman 1986, Lester 1995). Additionally, Lair (1996), Sheldon (1997) and Oliviere et al. (1998) argue that, owing to the nature of many life-threatening illnesses, the adjustments made by older people are mirrored by younger terminally ill people, often within a shorter time span. This places them under enormous pressure to achieve ego-integrity. The current study discusses how life review might assist younger people with a terminal illness to achieve ego-integrity.

\section{Life review and reminiscence}

Butler (1963) explicates the therapeutic value of life review by upholding that many of the problems faced by older people relate to their impending death and their need to talk about their lives. In this study life, however, review and reminiscence are not distinguished. Burnside and Haight (1994), Perlstein (1996) and Gatz et al. (1998) suggest, on the other hand, that reminiscence is typically less structured, often occurs as a 'one off' session or used recreationally, can be initiated during activities such as assisting with personal grooming or wound care and tends to focus on positive memories. Ashton (1993) and Hitch (1994) add that reminiscence tends not to be used for more recent events, but concerns rather memorable events from an individual's past. The recreational use of simple reminiscence may not assist the terminally ill patient as much as desired. People may harbour regrets over their life and wish to engage in deeper discussion and exploration of painful memories that require a focused and skilled approach such as that offered by structured life review.

Life review is considered by Butler (1963) to be a universally occurring mental process where people recall their life experiences and unresolved conflicts, which they evaluate and attempt to reconcile. However, the paucity of research into cultural diversity makes it difficult to assume 'universality'. Additionally, Merriam (1995) reports on the Georgia Centenarian Study part of which set out to test Butler's thesis. Findings indicated that $43.8 \%$ of centenarian's had not reviewed their lives, neither had $44.7 \%$ of
80 -year old and $51 \cdot 1 \%$ of 60 -year-old surveyed. Overall, $46.4 \%$ of the total sample said they had not reviewed their lives. A chi-square test revealed no significant differences between the three groups $(x=7.63038, \quad$ d.f. $=4$, $P=0 \cdot 1061)$. This study took place in the US and suggests that life review cannot be considered a common process even within the West, which tends to privilege the individual.

Erikson (1982), McDougall et al. (1997) and Dunn et al. (2002) consider life review as the process of organizing and evaluating the overall picture of an individual's life, aiming to enhance the later years through facilitating the achievement of ego-integrity. Life review is usually performed individually, covers the entire lifespan and addresses positive and negative experiences, both recently and in the past. It may also address areas of conflict and disturbance in a person's life (Lashley 1993, Silver 2002). Some of the reported benefits of life review include increased self-esteem, decreased depression, increased life satisfaction and improved socialization (Hitch 1994, McDougall et al. 1997). Peachey (1992) and Haight et al. (1998) believe that individuals unable to undertake life review may risk failure to affirm life, which may, in turn, lead to feelings of depression, hopelessness and despair.

\section{Studies advocating the use of life review in palliative care}

Clinical experience suggests that many terminally ill patients need to reflect upon their failures and achievements throughout their life. Oleson and Dulaney (1993), Soltys and Coats (1995) and Beechem et al. (1998) support this view, adding that many people may wish to identify negative life events and reintegrate them in order to grieve over their losses. Several writers suggest that life review may be valuable for younger people who are dying and experiencing 'crises' such as helplessness, despair and loss (Burnside \& Haight 1994, McDougall et al. 1997, Brady 1999, Trueman \& Parker 2004).

It is noted that during the past decade very little has been published in relation to the use of life review and younger dying people. Additionally, most literature advocating the use of life review in this context originates from North America building on Butler's underpinning theory (DeRamon 1983, Borden 1989, Pickrel 1989, Wholihan 1992). They add that many of the benefits of life review in terminally ill people, irrespective of their age, mirror those found in older people, including reaffirmation of self-esteem and identity and a reduction in feelings of loss or isolation. Such re-discoveries of the positive aspects of their life and the acquisition of some sense of life achievement may offer the dying person the opportunity to anticipate and grieve for the end of their life, 
thus having the potential to assist the patient in letting go. Pickrel (1989) argues that the imminence of death often stimulates the life review process, presenting with the person's desire to examine and evaluate their past, present and desired future. She remarks that, although a person may be in no hurry to die, the terminally ill person may be more able to accept death through the life review process, adding that successful life review is measured through their sense of satisfaction that they have done their best during the time they had available.

Oleson and Dulaney (1993), Beechem et al. (1998) and Brady (1999) suggest that a variety of different methods for undertaking life review exist. These include oral history, autobiography, family tree, genogram and lifeline adding that many 'props' can be used as catalysts for the process, for example photographs, scrapbooks, tape recordings or video. The majority however, appear to favour the use of a structured life span questionnaire or guide.

\section{The limitations of life review}

De-Ramon (1983) and Griffin-Moore (1992) warn of the possibility that the facilitator could raise issues that cause great emotional distress to the patient. Lashley (1993) argues that the distress may be so painful that they retreat into silent reminiscing and become despondent. In extreme cases, such despondency may lead the patient to believe their life has been meaningless and harbour feelings of despair and hopelessness (O'Connor et al. 1990, Lester 1995). Patients experiencing such feelings should never be left to face such despair alone and may require in depth support. Consequently, Hitch (1994) and Chochinov and Breitbart (2000) argue that it is vital that the facilitator is aware of their limitations and refer to appropriate professionals such as a clinical psychologists or psychotherapists if such feelings emerge. The fact that such contentions arise promotes the need for further research into this area of practice.

\section{Aims and objectives}

This descriptive study aims to explore community nurses' knowledge of life review in the delivery of palliative care with people who have a life threatening illness. The specific objectives of the study were to:

- Describe the participants' understanding of reminiscence and life review.

- Detail their current ideas regarding a structured approach to using life review in the community setting.
- Outline their understanding of the possible advantages and limitations of life review in relation to palliative care.

- Identify future training requirements.

\section{Design}

Since this study aimed to examine the participants' understanding of life review, a qualitative approach utilizing a descriptive design was considered appropriate. Descriptive designs are used for describing something where there is little theoretical or factual knowledge (Burns \& Grove 1997, Carter \& Porter 2000) and, this again, provides a rationale for the current study.

\section{Methods}

\section{Sampling}

The research population was community nurses who, in the course of their working duties, would deliver generic or specialist palliative care. The sample included district nurses, community staff nurses and clinical nurse specialists in palliative care. The sample was drawn from a target population of 68 community nurses working in one Primary Care Trust (PCT) (comprising all health care services within a specific geographical area and usually serving a population of around100 000 people) in Northern England. A purposive sample has been chosen for this study, described by Morse and Field (1996) and Holloway and Wheeler (1997) as a sample derived from the need to obtain specific information from specific individuals. A letter inviting each member of the target population to be involved in the study generated 21 respondents who were divided into three focus groups.

\section{Ethical considerations}

Permissions were sought from the appropriate agencies and from participants involved following the principles set out in the Declaration of Helsinki (World Medical Association 1989). The main constructs of the Declaration are summarized by Couchman and Dawson (1990), whose work identifies the key components of ethical research being: the individual's right to not be harmed, to informed consent, confidentiality, dignity, voluntary withdrawal, anonymity and self-respect. Therefore, a letter outlining the rights of the participants to withdraw from the research at any time, data handling and verification were sent to all participants, a copy of which was signed and served as informed consent. 
Furthermore, to limit any possible harm to the participants, details of an appropriately qualified colleague prepared to discuss, in confidence, any particular issues raised during the research was outlined.

\section{Data collection}

Data were collected through focus group interviews. Focus groups constitute an effective qualitative and exploratory method for collecting narrative data (Kitzinger 1994, Clifford 1996). They facilitate discussion among a group of individuals, whose values, experiences and opinions are sought (Powell \& Single 1996, Burrows 1998). Focus groups have the capacity to generate large quantities of data in a relatively quick and cost effective manner and the interaction between participants may reveal differences of opinion or elicit new avenues of discussion. Such divergence adds to the rich narrative data required for qualitative studies, which can be difficult to expose in an individual interview (Reed \& Payton 1997). They can, however, produce a 'group' response and so it must be acknowledged that some individual perspectives may not have been identified in the current research. During the interviews, the researcher acted as a non-directive moderator, whilst ensuring adherence to the desired area of discussion (Parahoo 1997, Burrows 1998). This study used two moderators; one a tutor with supplementary counselling qualifications who observed and recorded the non-verbal communication, whilst the researcher facilitated the discussion, using a list of discussion themes pertaining to the literature review and research question.

\section{Data management}

The tapes were transcribed verbatim as soon as possible after the interviews as directed by Morse and Field (1996). The significant statements that related to the research question were extracted and categorized. These categorized statements along with the transcripts were returned to the participants for comment to ensure a degree of accuracy in the interpretation. On completion of the study, the tapes were destroyed as outlined in the consenting letter.

\section{Data analysis}

First level coding involved line-by-line examination of the transcripts with significant statements relating to the research question being coded under several headings. Burrows (1998) suggest that cutting statements from a 'clean' copy of the transcript and pasting them to file cards can assist in the organization and refinement of categories. This method was used rather than computer software packages to gain a greater sense of 'immersion' in the data. Strauss (1987) and Reed and Payton (1997) suggest that each statement should also be identified in the transcript to ensure that all statements can be traced. This method of categorization and coding was labour intensive but ensured familiarity with the content of the transcripts.

The next stage of analysis involved 'data reduction'. Miles and Huberman (1994) suggest that this occurs through condensing and categorizing the initial codes. During this process of revision and refinement, several categories were linked and developed into sub-categories until 'theoretical saturation' of the data was achieved (Strauss 1987, Robson 2002).

\section{Validity and reliability}

According to Nyamathi and Shuler (1990) and Krueger (1994) focus groups typically have high face validity due to the credibility of the comments coming from the participants. Returning the categorized significant statements, along with the transcripts to the participants ensured greater accuracy of interpretation, thus enhancing the validity and trustworthiness of the data collected.

Reliability in qualitative research is difficult because the results are based on human subjectivity where there cannot be one 'truth' (Carter \& Porter 2000). However, within the three focus groups the participants generally discussed similar issues and raised similar points, indicating that as a method of data collection, there appeared to be a degree of consistency across the three focus groups.

\section{Results}

One hundred and fifty six significant statements concerning the perceptions community nurses had of life review were generated from the transcripts, which were reduced to six broad categories listed below.

- The similarities and differences between life review and reminiscence.

- The structure of life review.

- Relationship between reviewer and facilitator.

- Potential benefits of life review.

- Potential disadvantages of life review.

- Training issues.

The categories are derived from the most commonly occurring statements generated from the focus groups. The extracts in this section are direct quotations from the participants and are coded as letter = nurse, and number $=$ focus group for example, A1. 


\section{Similarities and differences between life review and reminiscence}

Most participants had never heard of life review or consciously used it before attending the focus group (B1, D2 and E3). Consequently, the participants were unable to offer a definition of life review. However, many participants suggested that life review was individualized, explored the entire lifespan in stages or 'chapters', focused on both positive and negative events, was patient-led and deeper than reminiscence. Conversely, they believed reminiscence to be more spontaneous, ad hoc, unstructured, undertaken in groups, only explored significant and positive events and tended to be a recreational activity. However many participants confused life review with reminiscence, particularly regarding the life span approach and structured format:

Reminiscence is a bit more focused and more structured (A1).

Well they just find themselves drifting into it (life review), I suppose (E2).

I think it (life review) is very spontaneous and informal (D3).

\section{Structure of life review}

Although participants had a superficial understanding of life review and were able to make some superficial distinction between life review and reminiscence, much of the debate within the groups centred on its structure. Initially, many participants had reservations about using a structured approach stating you tread on dangerous ground by doing a structured thing $(\mathrm{H} 2)$ :

If it (life review) was formatted or structured, then it would come across as a false intervention that would not be therapeutic (F1).

Such antipathy decreased as the participants began to explore the possible structured use of life review over several sessions. They drew similarities with nursing assessment, which often takes several visits to complete. The B1 suggested that life review was like a 'soap opera' where nurses tune in for weekly instalments. Although this analogy generated some laughter, one participant (F1) reminded the group that life did not have the benefit of a rehearsal.

Participants C2 and E3 believed they had previously discussed different stages of a patient's life over several weeks without realizing it was life review. This appeared to demonstrate a general lack of formal awareness suggesting the need for a clearer knowledge base. Several participants acknowledge that despite being perceived as false, a structured approach may enable people to divide their life into manageable segments, offering direction and assisting with 'closure' (D1, D2 and E3). Participant A1 gained consensus with the suggestion that the absence of a structured tool may create a situation where patients might be unsure upon what they were embarking.

\section{Relationship between the reviewer and facilitator}

All the focus groups concurred that the relationship needed to be based on trust, which usually developed over time, adding that community nurses were in an ideal situation to facilitate life review, as they were generally well known to their patients.

Furthermore, the participants believed that this relationship was influenced by the facilitator's range of interpersonal skills, including being non-judgmental and suppressing their shock. All the focus groups identified the importance of excellent interpersonal skills in the successful facilitation of life review. Participant F2 summed up the general mood of the groups with the suggestion that the nurse needs to act as an ear using silence appropriately because people close to death want to talk about their lives.

\section{Potential benefits of life review}

Despite the general lack of understanding regarding the mechanisms of life review, many of the ideas put forward in the focus groups regarding the benefits of life review tended to mirror those found in the literature. Additionally the groups were able to recognize the potential benefits for its use in palliative care:

It (life review) may help a person come to terms with their death or current situation (D2).

Helps people to focus on their achievements rather than their failures (B3).

Life review may help you to put your life in order and help people to validate themselves as individuals (E1).

\section{Potential disadvantages of life review}

This category arose out of the analogy 'opening a can of worms', which was raised within all the focus groups as a way to describe the potential problems associated with life review. Participants elaborated on this analogy, stating:

The person could be left with feelings of unfinished business and regrets and are too ill to do anything about, leaving the person emotionally distressed (G1). 
We shouldn't knock scabs off old wounds; I mean issues, which have been forgotten are forced to the surface (D2).

The very ambitious person may feel that through life review, they have failed (B3).

The most surprising theme emerging from first focus group was their concern over the potential harm to their own emotional well being whilst facilitating life review. Such was the strength of feeling that this theme was explored with subsequent groups. The responses were separated into three areas.

\section{Affecting the patient}

Nurses may not feel comfortable to go along a certain route and therefore prevent the patient from doing so, even when the patient wants to (D1).

\section{Affecting the nurse}

Listening to other people off loading their baggage can become a drain (G2).

\section{Support for the nurselfacilitator}

Nurses need support when undertaking life review, clinical supervision may do this (G1).

Teamwork may help give this support (D3).

The participants from all the focus groups recognized that such disadvantages demonstrated the importance of the facilitator to recognize their limitations:

When nurses are out of their depth, they may need to refer to counsellors, Psychotherapists, palliative care team and depending on the problem, voluntary Organizations (F2).

All the focus groups believed that it was important to recognize whether the referral was not only appropriate, but was also requested as some patients may have gained a sense of catharsis getting an issues 'off their chest' but would wish to take it no further.

\section{Training}

The final category arose out of the participant's recognition that they had a reasonable, but naïve and unformulated level of knowledge relating to life review. Most participants believed that inadequately trained facilitators could at best, be ineffective or at worst harmful (C1, H2 and D3). Most believed life review had significant possibilities in palliative care, but recognized the need for further training. Participants believed that training should focus on a particular structure or tool and many believed that interpersonal skills training should run concurrently.

\section{Discussion}

The discussion focuses on the three key issues arising from the results in relation to the research question, these were: factors affecting the patient, factors affecting professionals and factors affecting training.

\section{Factors affecting the patient}

Much debate centred on whether life reviews should adopt a structured lifespan approach or whether it was a more spontaneous intervention. Although a small number of participants argued for a more structured approach, the majority believed it to be unnecessary, contrived and risked encroaching into areas that patients did not wish to discuss. Such ideologies directly contrast the evidence found in the wider literature. A more structured approach usually assures a more chronological, and methodological lifespan approach, empowering patients to determine where they wish to take their life review (Wholihan 1992, Dunn et al. 2002). Furthermore, Beechem et al. (1998) discovered that facilitators using a prescribed life review interview guide had requested even more structure, believing it assisted in more effective life review.

Several participants were concerned that a structured, chronological approach may prevent patients from discussing matters requiring immediate action, which may have occurred in their later years. A number of authors uphold this view (Haight \& Burnside 1993, Silver 2002), arguing that it is more important that their entire life is reviewed over the duration of the sessions, rather than the order in which events occurred. They acknowledge, however, that patients not wishing to discuss certain periods of their life should have their silence respected.

Only one participant rightly identified that the absence of a structured format would probably increase the likelihood that both nurses and patients would be unsure if they were engaged in life review. Clearly, this raises ethical concerns whether informed consent had been sought before facilitating a patient's life review.

Borden (1989) and Haight and Burnside (1993) have established the importance of formulating a contract with the patient, outlining the key constructs of the intervention and the likely timescales. Lashley (1993) contends that a contract may ensure that the facilitator has offered a detailed explanation and is satisfied that the person understands the process. A contract is defined as a formal agreement (being 
legally or non-legally binding) between individuals or groups. It often sets out the terms of the agreement including the type of service offered and how it will be delivered (Cain et al. 1995). Additionally, the use of a contract may help to create a more predictable situation (Baggott 1994). A view supported by Doyle et al. (1998) who expound that even a simple verbal contract could help many terminally ill patients feel a reduction in the feelings of hopelessness by hearing that there is some future.

Although this issue was not raised within the focus groups, the use of a contract in this context holds links with informed consent, the dissemination and understanding of information to an individual (Duffin 2000, Department of Health 2001). The Nursing \& Midwifery Council (2002: clause 3) outline the importance of informed consent where nurses must ensure that the patient fully understands the treatment or intervention being offered. Therefore, it is clear that nurses facilitating life review must demonstrate a sound understanding of life review before its inception to ensure informed consent has been gained; the use of a contract may be one way of achieving this.

\section{Factors affecting professionals}

This issue was borne out of the participant's view that listening to people's life stories could potentially have a negative affect on their own emotional welfare. Whilst this aspect of life review had not been considered prior to the data collection, several writers acknowledge that facilitators must remain aware of the potential negative impact another's life review may have on feelings from their own past (Lashley 1993, Beechem et al. 1998). Furthermore some facilitators may feel 'stressed out' or struggle to organize their own thoughts and may wish to review their own lives to increase their understanding of life review (Haight \& Olson 1989, Lester 1995). Interestingly, it appears that relevant literature fails to identify possible strategies to ensure the facilitator's well being in such circumstances.

Several focus group participants identified clinical supervision as one possible strategy. Black and Haight (1992) and Soltys (1998) assert that facilitators should liaise closely with another professional, adopting the role of guide and sounding board. Clinical supervision offers the opportunity for reflection on practice, professional support and the development of professional knowledge and skills (Butterworth et al. 1998, Marrow et al. 1998). Social workers and counsellors are often required to engage in therapeutic relationships with their clients and the support extended to them through clinical supervision is deemed necessary and valuable (Alexander et al. 1994, Goorapah 1997, Tsui 2005). Some writers suggest that clinical supervision may help reduce the onset of stress and burnout (Kohner 1994, Howard 1998). Such views are validated by Butterworth et al. (1998) who propose that community nurses are often exposed to a high level of stress due to the isolated nature of working literally behind closed doors. Therefore, the research participant's belief that clinical supervision may assist in the reduction of negative feelings experienced through the facilitation of life review in palliative care may be justified.

\section{Factors affecting training}

The results have demonstrated that whilst most participants were able to explicate many of the benefits and possible limitations of life review and recognize the skills required to ensure its effective facilitation, their reticence to use a structured approach to life review indicated that they were confusing it with reminiscence. Therefore, due to the participant's level of knowledge regarding the use of life review, they would be unable to gain the informed consent of their patients competently, suggesting that the community nurses taking part in the study would currently be unable to incorporate life review into the palliative care package they offer.

Many of the participants recognized and indeed advocated the therapeutic possibilities of life review as an intervention for terminally ill patients receiving palliative care and were anxious to receive further training. Haight and Burnside (1993) suggest that health professionals require formal teaching regarding the differences between reminiscence and life review to assist in clarification of their objectives. Furthermore, such training should incorporate interpersonal, listening and facilitation skills (Wholihan 1992, Burnside \& Haight 1994).

\section{Limitations}

The limitations of the study relate in part to the limitations regarding focus group interviews. Holloway and Wheeler (1997) suggest that focus groups that comprise a diverse range of staff members, resulting in the possibility of some participants refraining from disagreeing with their senior colleagues. Kitzinger (1994) adds that 'group think' can occur where one member is dominating the discussion. However, all participants were encouraged to speak throughout and with the agreement of the observer; the transcripts demonstrated that despite some participants being more vocal, all participants regularly contributed to the discussion.

Due to the study being undertaken in one PCT couple with the relatively small number of participants, the study has little 
generalizability in the wider health care setting. It is also acknowledged that alternative results may have been obtained in different localities or from the wider multi-disciplinary team.

\section{Recommendations}

There was a general sense that the participants were positive towards the intervention and would welcome its implementation. However, there is a need for further training into all aspects of life review including the development of a specific tool/structure for palliative care. This has, in part been implemented in a number of local palliative care modules within two Universities through the inclusion of introductory sessions and a number of conference workshops (Trueman 2004).

To complement such training, it is recommended that facilitators be offered further opportunities to enhance their interpersonal skills. This has been addressed for senior community nurses through the funding made available to the 34 Cancer Networks for communication skills training that arose from the criticisms highlighted in the NHS Cancer Plan (Department of Health 2000). The final recommendation is that practitioners who do not currently access clinical supervision should consider requesting it before facilitating life review to help ensure their emotional well being.

\section{Conclusions}

The use of life review as an intervention for younger people in the palliative phase of a terminal illness is supported by several writers who contend that such people are catapulted to the developmental 'crisis' of ego-integrity vs. despair due to their shortened lifespan.

The support offered to patients requiring palliative care by community nurses often persists for several months. Such support generally focuses on the practical and physical aspects of a person's illness. Life review could offer a more structured approach, increasing the focus on the emotional needs of dying patients.

A series of focus group interviews demonstrated the participant's belief that life review would be a useful intervention in palliative care, although most were unsure of the structure or mechanism concerning its use, with many confusing it with reminiscence. Most participants identified their desire for further training in life review and in response; several recommendations have been made regarding possible future training, education and support for facilitators.

The authors are in the preliminary stages of a wider study using life review with terminally ill patients, which has raised a number of ethical issues that require consideration. The aim of the study is to generate further evidence to support nurses in the more structured use of life review with people requiring palliative care.

\section{Contributions}

Study design: IT, JP; Data collection: IT and manuscript preparation: IT, JP.

\section{References}

Alexander MF, Fawcett JN \& Runciman PJ (1994) Nursing Practice: Hospital and Home, the Adult. Churchill Livingstone, Edinburgh. Ashton D (1993) Therapeutic use of reminiscence with the elderly. British Journal of Nursing 2, 894-898.

Baggott R (1994) Health and Healthcare in Britain. Macmillan Press Ltd., London.

Beechem MH, Anthony C \& Kurtz J (1998) A life review interview guide: a structured approach to information gathering. International Journal of Aging and Human Development 46, 25-44.

Black G \& Haight BK (1992) Integrality as a holistic framework for the life review process. Holistic Nursing Practice 7, 7-15.

Borden W (1989) Life review as a therapeutic frame in the treatment of young adults with AIDS. Health and Social Work 14, 253-259.

Bornat J, Dimmock B, Jones D \& Peace S (2000) Researching the implications of family change for older people: the contribution of a life-history approach. In The Turn to Biographical Methods in Social Science: Comparative: Issues and Examples (Chamberlayne P, Bornat J \& Wengraf T eds). Routledge, London, pp. 219-241.

Brady ME (1999) Stories at the hour of our death. Home Healthcare Nurse 17, 177-180.

Brändstädter J \& Greve W (1994) The aging self: stabilising and protective processes. Developmental Review 14, 52-80.

Burns N \& Grove SK (1997) The Practice of Nursing Research, 3rd edn. W. B. Saunders Company, London.

Burnside I \& Haight BK (1994) Reminiscence and life review: therapeutic intervention for older people. Nurse Practitioner 19, $55-61$.

Burrows D (1998) Using focus groups in nursing research: a personal reflection. Social Sciences in Health 4, 3-14.

Butler RN (1963) The life review: an interpretation of reminiscence in the aged. Psychiatry 26, 65-76.

Butterworth T, Faugier J \& Burnard P (1998) Clinical Supervision and Mentorship in Nursing, 2nd edn. Chapman \& Hall, London.

Cain P, Hyde V \& Howkins E (1995) Community Nursing: Dimensions and Dilemmas. Arnold, London.

Caplan G (1961) An Approach to Community Mental Health. Grune and Stratton, New York.

Carter DE \& Porter S (2000) Validity and reliability. In The Research Process in Nursing, 4th edn. (Cormack DFS ed.). Blackwell Science Ltd., Oxford, pp. 29-40.

Chochinov HM \& Breitbart W (2000) Handbook of Psychiatry in Palliative Medicine. Oxford University Press, Oxford.

Clifford C (1996) Nursing and Health Care Research, 2nd edn. Prentice Hall, London. 
Coleman PG (1986) Ageing and Reminiscence Processes: Social and Clinical Implications. John Wiley \& Sons Ltd., London.

Coleman PG (1997) The last scene of all. Generations Review 7, 2-5.

Cook EA (1991) The effects of reminiscence on psychological measures of ego-integrity in elderly nursing home residents. Archives of Psychiatric Nursing V, 292-298.

Couchman W \& Dawson J (1990) Nursing and Health Care Research. Scutari Press, London.

Department of Health (2000) The NHS Cancer Plan. HMSO, London. Department of Health (2001) Good Practice in Consent: Achieving the NHS Plan Commitment to Patient-Centred Consent Practice. HMSO, London.

DeRamon PB (1983) The final task: life review for the dying patient. American Journal of Nursing 13, 44-49.

Doyle D, Hanks GWC \& MacDonald N (1998) Oxford Textbook of Palliative Medicine, 2nd edn. Oxford University Press, Oxford.

Duffin C (2000) Calling all the shots. Nursing Standard 15, 12-13.

Dunn PH, Haight BK \& Hendrix S (2002) Power dynamics in the interpersonal life review dyad. Journal of Geriatric Psychiatry 35, 77-94.

Erikson EH (1965) Childhood and Society. Penguin, Harmondsworth.

Erikson EH (1982) The Life Cycle Completed. Norton, New York.

Gatz M, Fiske A, Fox L, Kasl-Godley JE, McCallum TJ \& Wetherell JL (1998) Empirically validated psychological treatments for older adults. Journal of Mental Health and Ageing 4, 9-46.

Goorapah D (1997) Clinical supervision. Journal of Clinical Nursing 6, 173-178.

Griffin-Moore B (1992) Reminiscing therapy: a CNS intervention. Clinical Nurse Specialist 6, 170-173.

Haight BK \& Olson M (1989) Teaching Home Aides the use of Life Review. Journal of Nursing Staff Development January/February, 11-16.

Haight BK \& Burnside I (1993) Reminiscence and life review: explaining the differences. Archives in Psychiatric Nursing VII, 91-98.

Haight BK, Michel Y \& Hendrix S (1998) Life review: preventing despair in newly relocated nursing home residents, short and long term effects. International Journal of Ageing and Human Development 47, 119-142.

Havighurst RJ (1972) Developmental Tasks and Education, 3rd edn. David Mckay, New York.

Hitch S (1994) Cognitive therapy as a tool for caring for the elderly confused person. Journal of Clinical Nursing 3, 49-55.

Holloway I \& Wheeler S (1997) Qualitative Data Analysis. Blackwell, Oxford.

Howard D (1998) Stress and anxiety. In Nursing Knowledge and Practice: A Decision Making Process (Mallik M, Hall C \& Howard D eds). Bailliere Tindall, London, pp. 480-508.

Kitzinger J (1994) The methodology of focus groups: the importance of interaction between research participants. Sociology of Health and Illness 16, 103-121.

Kohner N (1994) Clinical Supervision in Practice. Kings Fund Centre, London.

Krueger RA (1994) Focus Groups: A Practical Guide for Applied Research, 2nd edn. Sage, California.

Lair GS (1996) Counselling the Terminally Ill. Taylor \& Francis Ltd., London.
Lashley ME (1993) The painful side of reminiscence. Geriatric Nursing 14, 138-141.

Lester J (1995) Life review with the terminally ill. Unpublished M.Sc. Dissertation. University of Southampton.

Marrow C, Yaseen T \& Cook M (1998) Caring together: clinical supervision, RCN Nursing Update, Learning Unit 77. Nursing Standard 12, 1-27.

McDougall GJ, Blixen CE \& Suen L (1997) The process and outcome of life review with depressed homebound older adults. Nursing Research 46, 277-283.

Merriam S (1995) Butler's life review: how universal is it? In The Meaning of Reminiscence and Life Review (Hendricks J ed). Baywood, Amityville, New York, pp. 7-20.

Miles MB \& Huberman AM (1994) Qualitative Data Analysis, 2nd edn. Sage Publications, London.

Miller C (1999) Nursing Care of Older People, 3rd edn. Lippincott, Philadelphia.

Morse J \& Field P (1996) Nursing Research: The Application of Qualitative Approaches, 2nd edn. Chapman \& Hall, London.

Nolan M, Davies S \& Grant G (eds) (2001) Working with Older People and Their Families: Key Issues in Policy and Practice. Open University Press, Buckingham.

Nursing \& Midwifery Council (2002) Code of Professional Conduct. Nursing \& Midwifery Council, London.

Nyamathi A \& Shuler P (1990) Focus group interviews: a research technique for informed practice. Journal of Advanced Nursing 15, 1281-1288.

O'Connor AP, Wicker CA \& Germino BB (1990) Understanding the cancer patients search for meaning. Cancer Nursing 13, 167-175.

Oleson M \& Dulaney P (1993) Life satisfaction, life review and near death experiences in the elderly. Journal of Holistic Nursing 11, 368-382.

Oliviere D, Hargreaves R \& Monroe B (1998) Good Practices in Palliative Care: A Psychological Perspective. Ashgate Publishing Ltd., Aldershot.

Parahoo AK (1997) Nursing Research: Principles, Processes and Issues. Macmillan Press Ltd., London.

Parker J \& Bradley G (2003) Social Work Practice: Assessment, Planning, Intervention and Review. Learning Matters, Exeter.

Peachey NH (1992) Helping the elderly person resolve ego-integrity versus despair. Perspectives in Psychiatric Care 28, 29-30.

Perlstein S (1996) Milestones in reminiscence. Journal of Long Term Home Health Care 15, 46-51.

Pickrel J (1989) Tell me your story: using life review in counselling the terminally ill. Death Studies 13, 127-135.

Phillipson C (1998) Reconstructing Old Age: New Agendas in Social Theory and Practice. Sage, London.

Powell R \& Single H (1996) Focus groups. International Journal of Quality in Health Care 8, 499-504.

Rancour P (2002) Catapulting through life stages: when younger adults are diagnosed with a life-threatening illness. Journal of Psychosocial Nursing 40, 33-37.

Reed J \& Payton VR (1997) Focus groups: issues of analysis and interpretation. Journal of Advanced Nursing 26, 765-771.

Robson C (2002) Real World Research, 2nd edn. Blackwell, Oxford. Seale C (1992) Community nurses and the care of the dying. Social Science Medicine 34, 375-382. 
Sheldon F (1997) Psychosocial Palliative Care. Stanley Thornes Ltd., Cheltenham.

Silver MH (2002) The significance of life review in old age. Journal of Geriatric Psychiatry 35, 11-23.

Soltys FG (1998) Helping families face the end of life. Adult Service Practice Notes 1, 1-5.

Soltys FG \& Coats L (1995) The SolCos model: facilitating reminiscence therapy. Journal of Psychosocial Nursing 33, 21-26.

Strauss AL (1987) Qualitative Analysis for Social Scientists. Cambridge University Press, Cambridge.

Trueman I (2004) Life review - an educational perspective. In Delivering Cancer and Palliative Care Education (Foyle L \& Hostad J eds). Radcliffe Medical Press Ltd., Oxon, pp. 161-173.
Trueman I \& Parker J (2004) Life review in palliative care. European Journal of Palliative Care 11, 249-253.

Tsui MS (2005) Social Work Supervision: Contexts and Concepts. Sage, London.

Wholihan D (1992) The value of reminiscence in hospice care. The American Journal of Hospice \& Palliative Care March/April, 3335.

World Medical Association (1989) Declaration of Helsinki. The World Medical Association Handbook of Declarations. In Researching Palliative Care (Field D, Clark D, Corner J \& Davis C eds). Open University Press, Buckingham. 
This document is a scanned copy of a printed document. No warranty is given about the accuracy of the copy. Users should refer to the original published version of the material. 